\title{
53. Communicating climate change science to diverse audiences
}

\author{
Asmeret Asefaw Berhe
}

\section{BACKGROUND}

As impacts of climate change continue to receive widespread global attention, the calls for better science communication around issues of climate change have been growing. Scientists and other practitioners are being urged to effectively communicate the science of climate change, the impacts that are likely to be felt by different segments of the human community, and the dangers of doing nothing to mitigate impacts of climate change in a manner that is accessible to a wide segment of society. In recent years, the calls have also been growing to ensure that we employ equity-oriented approaches, and value and include traditionally underserved and minoritized communities in our science communication efforts (Dawson, 2014; Streicher, Unterleitner and Schulze, 2014). Doing so requires that we employ a climate change science communication strategy that centers on equity and inclusion of people from all walks of life; and that we intentionally and explicitly address historic inequities with access to science and all other scholarly opportunities (Canfield et al., 2020).

An inclusive climate science communication strategy is one that values and explicitly acknowledges historical, socio-economic, and political factors that are the root causes of the climate crisis, and aims to ensure that the same factors don't guide the communication or policy decisions around climate change mitigation and adaptation efforts. It requires that we explicitly acknowledge the root causes of the current environmental crisis, including human-induced climate change; that is, to name a few causes, unsustainable extraction of global natural resources; excesses and wasteful cultures associated with capitalistic economies; patriarchal systems that have limited women's education and professional aspirations; colonial regimes and associated political institutions that have continued to exploit a segment of the human population for the benefit of a few, and so on. Beyond acknowledging the relevant root causes of the ongoing climate crisis, an effective climate science communication strategy also recognizes that we must be cognizant of 
the need to reach audiences where they are, including when we communicate technical information to audiences with no technical background; to help our audience establish personal, moral, and/or emotional connections with the topics we are communicating; and to aim for participatory communication models that recognize marginalized and minoritized communities likely have relevant knowledge that should be considered (ibid.). Here I draw upon my experience communicating the science of soils and, in particular, the role of soils in the maintenance of the Earth's climate and contemporary climate change. I highlight how diversity in the messenger and tailoring our messages to our audience helps in science communication.

\section{COMMUNICATING THE ROLE OF SOILS IN CLIMATE CHANGE}

My personal work on science communication has largely been focused on topics of soil science, land degradation, and climate change science. Specifically, I have worked to improve societal understanding of the role of soils in regulating the Earth's climate, and how soil is and should be an integral component of any climate change mitigation strategy. This has meant that I have to communicate some complex concepts in soil and climate sciences to audiences that have varied from elementary school children to scholars and entrepreneurs across the world. Some key lessons I have learned in my experience include the need to explain why I think everyone should care about continuing degradation of the soil resource globally and the benefits of improving soil health, rates and sources of global climate change, and the relationship between the two global and very pressing contemporary phenomena - human-caused climate change and soil degradation. Below, I highlight some of what I have learned in my efforts to effectively communicate scientific concepts and ideas with diverse audiences.

\section{Communicating Climate Change Science}

Climate change impacts are felt differently by different segments of society and individuals with diverse backgrounds, ranging from land managers, residents of small island nations or coastal communities, consumers of products that rely on fossil fuels, educators, policy-makers, and more. Members of the scientific community are currently being called into action to educate the population on the science of climate change and engage in intellectual and political exercises to get climate change onto the movement agendas of the highest levels of national, regional, and international political organizations. A combination of coordinated and grassroots communication strategies is striving to ensure that all stakeholders understand the impacts of climate change and 
implications of not acting in a timely manner. Climate change communication is usually highlighted as being a difficult problem that is complicated by: the distant nature of the problem (in space and time for most individuals and communities), complexity of the scientific concepts behind the issue, and the lack of relevant education by most of the audiences we are trying to reach; varying levels of uncertainty in the data or expected outcomes being communicated (Ballantyne, 2016); and because of the ongoing, concerted efforts to deny the causes and consequences of human-caused climate change. An effective climate change communication strategy then needs to not just educate diverse populations about the problem, but also seek their engagement to overcome the above-listed hurdles.

\section{Communicating the Role of Soils}

A major and common challenge around communicating the role of soils in climate change is the fact that most adults have never learned about the science of soils, let alone how it is related to maintenance of the Earth's climate and contemporary climate change. Almost all people understand that virtually all their food is grown in soil, but only a very small percentage of the population (in particular, in urban areas) can articulate any other ecological role of soil. Soil is then widely perceived as just a few feet of unconsolidated mixture of mineral and organic matter with limited roles or benefits in the Earth system that are restricted to the agricultural or food production sectors. And this lack of familiarity with soil science is further compounded by deep-seated ignorance and dismissal about the resource base that is routinely treated as being useless stuff, which we can afford to take for granted. I regularly ask students and other audiences that I engage with what is the first thing that comes to their mind when they think of soil. The overwhelming response that I get is that soil is dirt. People use the words 'soil' and 'dirt' interchangeably. For all essential purposes, soil is treated as dirt and hence as something that is not clean, is worthless, and a nuisance. Communicating the role of soils in climate change then requires reminding folks first how the ground they walk on supports life in the Earth system, how precious the soil resource is, and about how contemporary land use systems have already caused significant degradation of soil globally. Afterwards, we can have a discussion about embracing sustainable land stewardship practices and consumers' willingness to compensate land managers for the cost of sustainably managing land to ensure the food and nutritional security of the growing human population and effective climate change mitigation.

Most audiences I engage with, at times even scientific audiences outside earth and environmental sciences, are surprised to learn that soil stores twice as much carbon as all the plants on Earth plus the atmosphere combined and 
has the power to shape our planet's destiny. It is not common knowledge that the ongoing climate crisis is partly a result of large amounts of carbon released to the atmosphere from the terrestrial biosphere by human activity that includes deforestation and changes in land use across the globe (Amundson et al., 2015). Once I highlight how much carbon is stored in soil, I then proceed with communicating the role of soils in climate change by highlighting that small changes in the amount of carbon stored in soil, and fluxes of carbon to and from soil and the atmosphere can have a big impact in maintenance of the Earth's climate.

Similar to the discussions around climate change, at times science communication around soil carbon sequestration and generally the role of soils in climate change is complicated by varying levels of uncertainty associated with different estimates of the potential for soil to sequester atmospheric carbon dioxide; the fast-changing pace of science in this pressing area of research; and disagreements in the scientific literature, public and professional society meetings and even social media between those who advocate soil $\mathrm{C}$ sequestration as being a critical component of any effective climate change mitigation strategy and those that argue that the role of soils is limited, and hence we should stop highlighting the role of soils in climate change too much. This kind of debate is, of course, how science advances in our professional spaces of education and research. But, it takes a different note when we carry it into the public sphere where we give our audiences the impression that: there are still too many uncertainties and we don't know much about the processes of carbon sequestration in soil; that soil carbon sequestration is not likely to have a too significant contribution to climate change mitigation (Schlesinger and Amundson, 2019); it is not realistic to expect land managers to carry out large-scale regenerative agriculture (Amundson and Biardeau, 2018); or that the focus on soil carbon sequestration is only limited to climate change mitigation and that if we address fossil fuel emissions we might as well forget about other benefits of soil carbon sequestration (Schlesinger and Amundson, 2019). Of course, none of these points is 100 percent true. Yes, there are challenges to scaling up what we have learned from small-scale studies to a global scale, and we do recognize that determining rates of carbon sequestration that can be achieved with climate-smart land management practices can vary across the word (Paustian et al., 2016). We do understand a whole lot about the process of carbon sequestration and even its limits under a variety of soil, climate, and management conditions. We also recognize that the benefit of carbon sequestration is not limited to climate change mitigation (Chabbi et al., 2017; Rumpel, Lehmann and Chabbi, 2018). We have known for decades, if not longer, that carbon sequestration in soil is key to soil health, for water and nutrient storage and availability in soils, the ability of soils to withstand erosion, the ability to support plant productivity, and so on. Hence, even if the benefits to climate 
change mitigation are limited, any amount of additional atmospheric carbon dioxide that is removed from the atmosphere and sequestered in the soil system has multiple beneficial contributions to improving soil health.

In my science communication efforts on this topic then, I have chosen to highlight the overarching benefits of soil carbon sequestration to improve soil health and contribute to climate change mitigation. Without shying away from acknowledging the uncertainties, I have sought to shine a light on why investing in scientific and policy solutions that can simultaneously seek to address the global problems of soil degradation and climate change is a win-win strategy that would address two of the most challenging environmental issues of our times.

\section{DIVERSITY IN SCIENCE COMMUNICATION}

\section{Messenger Matters}

An important variable to consider in any scientific communication strategy is that personal connections with our audience are key. As in any science communication, but especially science communication that affects the health and welfare of communities, the identity of the messenger, prevailing socio-political issues, and history, matter - a lot. Histories of colonialism, slavery, racial and gender-based oppression, and other injustices perpetuated by certain segments of society on others globally mean that marginalized and minoritized communities will rightfully be weary of who is framing and communicating issues of concern to them. They will wonder if the messenger has their welfare at heart. Even if the messenger does have their welfare at heart, do they trust the messenger, do they have any reason to? Hence, it is important that we establish trust with the communities we wish to communicate with ahead of time and give them reasons to trust us. Scientific debates sometimes tend to be polarizing, and especially if any issues with science-denial or distrust of authority figures are involved, it could quickly segregate our target audiences based on whether or not they are familiar with the processes of scientific reasoning or if they value scientific evidence. While these issues are ongoing then, the last thing we need is for our audience to also be wondering if the messenger shares cultural and other personal values with them. Even when communicating empirical data then, community representation and establishing trust with our audiences makes it more likely that they would believe the message we are delivering to them (Kahan, 2010). 


\section{Reflecting on Issues Relevant to Specific Audiences}

Effective science communication strategy that is meant to reach a diverse audience has to center equity and inclusion (Canfield et al., 2020). We must be able to focus on relevant history and ensure that we are telling inclusive stories that represent the communities we are trying to engage. An inclusive science communication strategy includes appropriate language, visual representations of the values of the messenger and inclusion, and explicit discussions about the rationale for action. For example, using examples of polar bears dying in the Arctic in our attempt to communicate climate change impacts to communities in Sub-Saharan Africa that are struggling with drought and other climate change effects on their food production system will obviously be off the mark. Similarly, attempts to communicate issues of how climate change is affecting the cost of fresh fruits and vegetables in the Central Valley of California to audiences living in urban deserts in the inner-cities of Detroit or Chicago is not likely to get the kind of desired attention from communities that are already struggling to get access to basic life-sustaining supplies. All the above-mentioned issues are important in their own right and are even interrelated. But, if we start with a framing that suggests that we care more about issues affecting people that are far removed from the specific community we are communicating with, or even worse non-human life forms, or if we fail to acknowledge that we care about the same things our audiences also care about, we are likely going to lose their interest. And they may tune out, thinking that climate change has nothing to do with them, and that they might not be affected, at least not anytime soon and it is a bigger issue to communities somewhere else that should care and do something about it now.

Furthermore, engaging a diverse audience in effective science communication requires that we are willing to practice participatory and inclusive approaches that consider the backgrounds, experiences, and traditional knowledge of our audiences. An inclusive science communication strategy stays away from using a deficit model that considers our audiences, especially those from underserved and minoritized communities, as lacking and less than others in their understanding of the science or ability to pursue science-informed policy goals (National Academies of Sciences, Engineering and Medicine, 2017). We must make it clear that we value and understand the traditional knowledge different communities have amassed over generations. If we demonstrate that we are open to learning from each other, it is then easier to earn trust that we aim to build a supportive community around a set of shared values around climate change and related fields. Moreover, if we establish trust with our audience, then it becomes easier to convince our audiences that, when traditional knowledge doesn't cover certain topics in a manner that science 
does, or if certain scientific concepts become too complicated they can trust the scientific approach (see Chapter 44 by Claude Henry in this book).

A science communication strategy that aims to engage a wide and diverse audience would also be served well if we acknowledge, advocate for, and practice any number of the proven benefits of diversity in all aspects of scholarly endeavors and science communication work. For example, we can highlight that we aim to ensure equity and inclusion in our communication because we acknowledge that involvement of diverse teams (across any number of diversity axes, including race, gender, religion, geographic origin, etc.) typically leads to excellence (Milem, 2003). Furthermore, we can explicitly recognize that the solutions that we desire to produce from the communication efforts and beyond have a far better chance of succeeding if they incorporate issues and ideas from all stakeholders; and that doing so opens opportunities for broader societal access to science education (National Academies of Sciences, Engineering and Medicine, 2017).

\section{REFERENCES}

Amundson, R., Berhe, A.A. and Hopmans, J.W. et al. 2015. Soil and human security in the 21st century. Science, 348 (6235), 1261071.

Amundson, R. and Biardeau, L. 2018. Opinion: soil carbon sequestration is an elusive climate mitigation tool. Proceedings of the National Academy of Sciences, 115 (46), 11652-6.

Ballantyne, A.G. 2016. Climate change communication: what can we learn from communication theory? Wiley Interdisciplinary Reviews: Climate Change, 7 (3), 329-44.

Canfield, K.N., Menezes, S. and Matsuda, S.B. et al. 2020. Science communication demands a critical approach that centers inclusion, equity, and intersectionality. Frontiers in Communication, 5 (2). https://doi.org/10.3389/fcomm.2020.00002.

Chabbi, A., Lehmann, J. and Ciais, P. et al. 2017. Aligning agriculture and climate policy. Nature Climate Change, 7 (5), 307-9.

Dawson, E. 2014. Reframing social exclusion from science communication: moving away from 'barriers' towards a more complex perspective. Journal of Science Communication, 13 (2), 1-5.

Kahan, D. 2010. Fixing the communications failure. Nature, 463 (7279), 296-7.

Le Quéré, C., Andrew, R.M. and Friedlingstein, P. et al. 2018. Global carbon budget 2018. Earth System Science Data, 10 (4), 2141-94.

Milem, J.F. 2003. The educational benefits of diversity: evidence from multiple sectors. In M.J. Chang, D. Witt, J. Jones and K. Hakuta (eds), Compelling Interest: Examining the Evidence on Racial Dynamics in Higher Education, Stanford, CA: Stanford University Press, pp. 126-69.

National Academies of Sciences, Engineering and Medicine. 2017. Communicating Science Effectively: A Research Agenda. Washington, DC: National Academies Press.

Paustian, K., Lehmann, J. and Ogle, S. et al. 2016. Climate-smart soils. Nature, 532 (7597), 49-57. 
Rumpel, C., Lehmann, J. and Chabbi, A. 2018. '4 per 1,000' initiative will boost soil carbon for climate and food security. Nature, 553 (7686), 27.

Schlesinger, W.H. and Amundson, R. 2019. Managing for soil carbon sequestration: let's get realistic. Global Change Biology, 25 (2), 386-9.

Streicher, B., Unterleitner, K. and Schulze, H. 2014. Knowledge rooms - science communication in local, welcoming spaces to foster social inclusion. Journal of Science Communication, 13 (2), C03. 